\title{
DAKWAH INKLUSIF DI KOTA PAREPARE
}

\author{
Iskandar, Natsir Mahmud, Darussalam Syamsuddin, Usman Jasad \\ Institut Agama Islam Negeri (IAIN) Parepare \\ Email: Iskandar@stainparepare.ac.id
}

\begin{abstract}
The results of this dissertation research show (1) the orientations of the inclusive insightful da'wah materials in Parepare city are that da'i must be sincere, that da'i becomesa role model, that da'i always learns and upgrades knowledge. Inclusive da'wah should use local languages, straightforward ways, narrative-substantive da'wah without indoctrination, calm and wise da'wah. Da'wah should be suitable to the needs of mad'u, suitable to the development of science and technology, and the level of knowledge of mad'u. Inclusive Da'wah is carried out based on da'wah maps andits relevance to plural societies. It should encourage social transformation, can be applied, and carried out in a dialogical manner; (2) The obstacles of inclusive da'wah are fanatical people, da'wah that does not enlighten and educate, da'wah that is not in accordance with the situation, conditions and ways of thinking of the people, da'wah that does not useBuginese language, preserved Buginese culture, da' $i$ who are not yet competent, not communicative, and generally still low in IT skills; (3) The solutions to the obstacles of inclusive da'wah are that there should be a mapping of da'wah in Parepare city, the Regional Government and Ministry of Religious Affairs must be synergistic, da'i should master the local language namely Buginese, da'i should be trained. Inclusive da'wah should be comprehensive, affordable access to the society, having syllabus, enlightening da'wah, and da'i who has competence, integrity and exemplary profile.

The implications of this research are that (1) the Regional Government of Parepare must take care of the tolerance and harmony of the Parepare city society, (2) the Ministry of Religious Affairs of Parepare makes a map of da'wah, trains da'i, compensates da'i, etc.; (3) the Indonesian Ulema Council becomes a representative forum for the people and carries out its main duties and functions; (4) Religious Social Organizations train their da'i professionally and responsibly; and (5) Da'wah practitioners always develop their competence and qualifications, master Arabic, Indonesian, and Buginese, master Information and Communication Technology, and protect them selves to have personality integrity.
\end{abstract}

Keywords: Dakwah Inklusif 


\section{PENDAHULUAN}

Islam sebagai agama dakwah yang dalam aplikasinya ditujukan kepada seluruh manusia, ${ }^{1}$ memunyai model dakwah yang sangat inklusif dan toleran sebagaimana yang telah dicontohkan oleh Rasulullah Saw. Dalam pengembangan Islam di Madinah sesuai petunjuk Alquran. Inklusifisme dan toleransiisme dalam aplikasi dakwah merupakan sikap yang berpandangan bahwa di luar faham keagamaan yang diyakininya juga terdapat kebenaran dan jalan keselamatan, meskipun tidak seutuh atau sesempurna faham keagamaan yang dianutnya. ${ }^{2}$

Sikap inklusif dan toleransi ini tampaknya kurang diperhatikan dalam pengembangan dakwah. Akibatnya, tidak jarang manusia, masyarakat, bangsa, baik secara interen umat Islam terlebih terhadap non Islam sering terjadi kesalahpahaman dan konflik sebagai refleksi dari sikap eksklusif keberagamaan atau paham, sikap intoleran apa lagi jika dipayungi dengan "monisme" di tengah keanekaragaman aliran/faham. Padahal dakwah Islam tetap diharapkan menjadi penyejuk hati dan tulang punggung peradaban manusia. Jika visi ini menjadi kesepakatan, maka perlu adanya reformulasi model pengembangan dakwah yang adaptif yakni konsep dakwah Islam yang berwawasan inklusif dan toleran berlandaskan pada etika keilmuan menurut Islam yang akan melahirkan suatu sikap toleran dalam aksi keberagamaan di tengah kemajemukan aliran/faham.

Menyikapi permasalahan seperti itu, penulis mengangkat judul yaitu “ Dakwah berwawasan Inklusif di Kota Parepare" dengan harapan agar dapat menumbuhkan kesadaran moral bahwa berdakwah bukan sekedar menjalankan kewajiban tetapi juga sebagai upaya aktualisasi nilai-nilai Islam sebagai agama

${ }^{1}$ Departemen Agama RI., Sejarah Pendidikan Islam (Jakarta : Proyek Pembinaan Prasarana dan sarana Perguruan Tinggi Agama Islam, 1986), h. 14.

${ }^{2}$ Ghazali, Agama dan Keberagamaan, Tp.T.th. h. 154. dan, Misrawi, Alquran Kitab Toleransi,Tp.T.th. h. 199. 
"rahmatan lil 'alamin " yang aktualisasinya harus lebih ditekankan pada nilainilai universal, khususnya di kalangan masyarakat Kota Parepare.

\section{PEMBAHASAN}

\section{Orientasi Materi Dakwah yang Berwawasan Inklusif Di Kota Parepare}

Dakwah inklusif merupakan suatu motode dakwah yang dinilai relevan pada masyarakat yang heterogen (majemuk). Masyarakat heterogen diperlukan cara pandang inklusif yakni mengakui adanya keragaman adalah merupakan sunnatullah. ${ }^{3}$ Masyarakat kota Parepare adalah masyarakat yang majemuk, sehingga diperlukan cara pandang yang inklusif dalam melihat realitas kehidupan. Adanya kesadaran tentang perbedaan merupakan takdir Ilahi, hal tersebut berimplikasi kepada bentuk pemikiran dan tindakan arif dan bijaksana terhadap pluralitas.Bagian inilah menjadi tugas da'i dalam membangun kesadaran masyarakat kota Parepare untuk menghargai perbedaan, menghormati keyakinan, bersinergi terhadap kehidupan dalam bingkai kemanusiaan.

Konteks keagamaan, masyarakat telah menjadi bagian dari kemajemukan.Kemajemukan agama dalam suatu masyarakat dapat menjadi spirit dalam interaksi dan sinergi menuju kemajuan dan dialektika sosial.Dalam masyarakat yang plural, diperlukanpemikiran dan sikap inklusif yang berpandangan bahwa di luar agamayang dianutnya juga terdapat kebenaran, meskipun tidak seutuh dan sesempurna agama yang dianutnya. ${ }^{4}$ Orang beragama diharuskan untuk meyakini kebenarannya dalam doktrin teologinya, namun bukan menjadi alasan untuk menyalahkan keyakinan yang berbeda dengannya.Keyakinan dalam keberagamaan merupakan suatu pintu pencarian kebenaran, dan bagi Islam merupakan pintu yang lebih representatif dilewati dalam melakoni kehidupan di dunia dan akhirat.

${ }^{3} \mathrm{Abu}$ Amar Bostami, "Prospektif Pesantren dalam Konstruksi Sosial Budaya Multikultural Masyarakat Indonesia", Jurnal Tarbawi, Vol. 1, No. 1, 2016, h. 1.

${ }^{4}$ Komaruddin Hidayat, "Ragam Beragama", dalam Andito, Ed., Atas Nama Agama, Wacana Agama, dalam Dialog “Bebas” Konflik (Bandung: Pustaka Hidayah, 1998), h. 119-122. 
Islam mengajarkan bahwa kemajemukan adalah ketentutan Allah Swt. Nabi Muhammad Saw., menginformasikan kepada umatnya untuk saling menghargai dan menghormati di antara sesama. Firman Allah Swt., dalam Q.S. Al-Hujurat/49: 13, yang berbunyi:

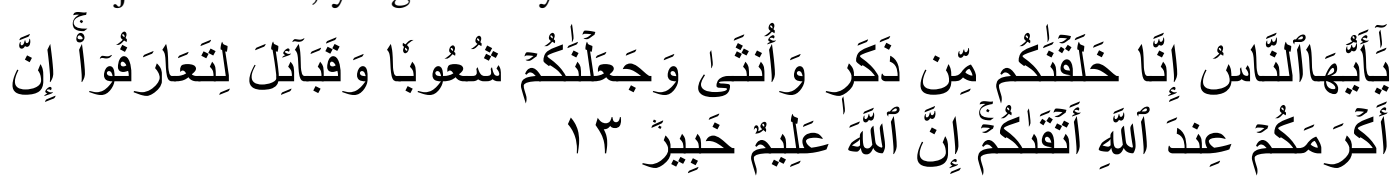

Terjemahnya:

"Hai manusia, sesungguhnya Kami menciptakan kamu dari seorang laki-laki dan seorang perempuan dan menjadikan kamu berbangsa-bangsa dan bersuku-suku supaya kamu saling kenal-mengenal.Sesungguhnya orang yang paling mulia diantara kamu disisi Allah ialah orang yang paling takwa diantara kamu.Sesungguhnya Allah Maha Mengetahui lagi Maha Mengenal."5

Ayat di atas menegaskan bahwa Allah menciptakan manusia dengan kemajemukan dari berbagai aspek, budaya, bangsa, agama, suku, dan lain sebagainya. Tidak boleh saling mencela dan menghina di antara sesame manusia, karena yang termulia di depan Allah adalah orang paling tinggi ketakwaannya. Islam pada hakekatnya sejalan dengansemangat kemanusiaan yang universal.Karena itu Islam adalah suatusistem yang menguntungkan semua orang, termasuk mereka yangbukan Muslim, dan juga karena itulah Islam bersifat inklusif. ${ }^{6}$ Islam sebagaimana diketahui sebagai agama rahmatan lil 'alamin, esensinya selalu menebar kasih sayang kepada semua makhluk Allah Swt., tanpa harus melihat latar belakang keagamaan seseorang.Semakin teguh iman dan massif ketakwaan, maka pancaran Islam menebarkan kasih sayang juga semakin intens dan bermakna.

Allah Swt., mengingatkan kepada hamba-Nya bahwa Islam merupakan agama penutup dan sempurna, bukan berarti kitab sebelum Alquran adalah salah. Keberpihakan kepada Alquran karena diyakini sebagai kitab yang lurus dan

\footnotetext{
${ }^{5}$ Kementerian Agama RI., Alquran dan Terjemahnya, h. 233

${ }^{6}$ Nurcholish Madjid, "Cita - Cita Politik Kita", dalam Bosco Carvallo dan Dasrizal, ed., Aspirasi Umat Islam Indonesia (Jakarta: Leppenas, 1983), h. 7.
} 
sempurna, dan tidak mengajarkan mencela sesuai hawa nafsu.Islam mengajarkan untuk saling memotivasi menyebarkan kebaikan kepada sesame untuk mencari keridhaan-Nya. Firman Allah Swt., dalam Q.S. Al-Maidah/5: 48 :

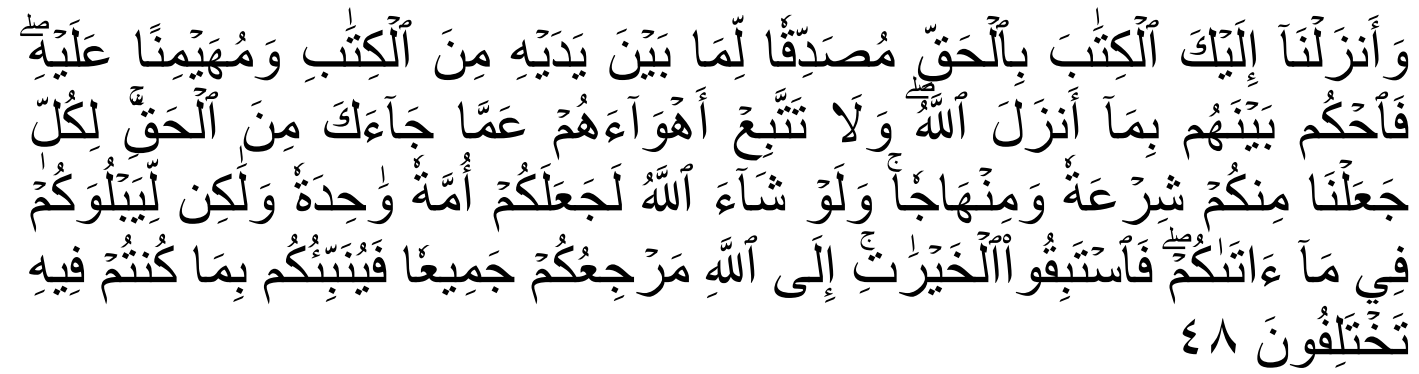

Terjemahnya:

Dan Kami telah turunkan kepadamu Alquran dengan membawa kebenaran, membenarkan apa yang sebelumnya, yaitu kitab-kitab (yang diturunkan sebelumnya) dan batu ujian terhadap kitab-kitab yang lain itu; maka putuskanlah perkara mereka menurut apa yang Allah turunkan dan janganlah kamu mengikuti hawa nafsu mereka dengan meninggalkan kebenaran yang telah datang kepadamu. Untuk tiap-tiap umat diantara kamu, Kami berikan aturan dan jalan yang terang.Sekiranya Allah menghendaki, niscaya kamu dijadikan-Nya satu umat (saja), tetapi Allah hendak menguji kamu terhadap pemberian-Nya kepadamu, maka berlombalombalah berbuat kebajikan. Hanya kepada Allah-lah kembali kamu semuanya, lalu diberitahukan-Nya kepadamu apa yang telah kamu perselisihkan itu. $^{7}$

Ayat di atas tampak menjelaskan bahwa setiap konflik dan perselisihan dalam keagamaan memiliki motif dan kepentingan.Motif dan kepentingan tersebut telah direkam oleh Allah Swt., dan itu semua adalah bagian dari ujian-Nya dalam mempertahankan dan menegakkan kebenaran.Ujian Allah terhadap manusia dalam memaknai perbedaan dan kemajemukan, dapat berbentuk penggunaan nalar (akal) dalam melihat secara objektif ciptaan Allah Swt., dan dapat juga berbentuk ketertundukkan kepada hawa nafsu karena ambisi dan keterbatasan ilmu pengetahuan. Umat Islam diharapkan selalu berpegang teguh kepada jalan yang telah ditetapkan oleh Allah Swt., karena nanti akan dimintai pertanggungjawabannya pada hari yang telah ditetapkan. Firman Allah Swt., dalam Q.S. Al-Baqarah/2: 148:

${ }^{7}$ Kementerian Agama RI., Alquran dan Terjemahnyah. 199 


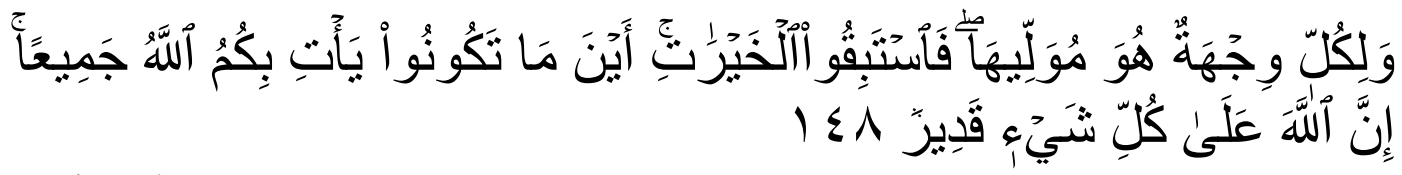

Terjemahnya:

Dan bagi tiap-tiap umat ada kiblatnya (sendiri) yang ia menghadap kepadanya. Maka berlomba-lombalah (dalam membuat) kebaikan. Di mana saja kamu berada pasti Allah akan mengumpulkan kamu sekalian (pada hari kiamat). Sesungguhnya Allah Maha Kuasa atas segala sesuatu.

Islam memiliki garis kebenaran yang jelas, begitu juga dengan agama dan keyakinan yang lain. Perbedaan garis kebenaran adalah sebagai bagian dari rahmat Allah, sehingga didorong bersifat arif dan bijaksana dalam menyikapi kemajemukan.Ajaran Islam itu bersifat inklusif.Islam menghendaki suatu sistem yang menguntungkan semua orangtermasuk mereka yang bukan-Muslim. ${ }^{8}$ Islam yang autentik akan berimplikasi kepada seluruh umat manusia, baik muslim maupun non muslim. Islam menjadi agama wasathan yakni ajaran moderasi dan keseimbangan, agar harmoni hidup dapat terpelihara dan dikembangkan.Dengan demikian, inklusifisme Islam memiliki komitmen yang kuatterhadap pluralisme, yaitu sistem nilai yang memandang secara positif-optimis terhadap kemajemukan, dengan menerimanya sebagaikenyataan dan berbuat sebaik mungkin atas dasar kenyataan itu. ${ }^{9}$

Dakwah Islamiyah di kota Parepare penting dikembangkan secara inklusif karena tipologi masyarakatnya yang majemuk.Kemajemukan masyarakat kota Parepare menjadi sebuah keniscayaan dan sudah menjadi budaya yang mengakar dalam membangun toleransi dan kerukunan hidup. Dakwah inklusif memiliki peran strategis dikembangkan pada masyarakat kota Parepare sebagai upaya melahirkan kesadaran akan perbedaan dan menciptakan kebersamaan, persaudaraan, dan kedamaian di tengah kemajemukan. Oleh sebab itu,

${ }^{8}$ Nurcholish Madjid, “Islam Inklusif”, dalam Budhy Munawar-Rachman, ed., Cendekiawan \& Religiusitas Masyarakat, Kolom-Kolom di Tabloid Tekad (Jakarta: Paramadina, 1999), h. 13.

${ }^{9}$ M. Syafi'iAnwar, "Sosiologi Pembaruan Pemikiran Islam Nurcholish Madjid," Ulumul Qur'an, Volume 1, 1993, h. 53. 
implementasi dakwah inklusif pada masyarakat kota Parepare, ada beberapa yang perlu menjadi perhatian oleh seluruh komponen yang terkait, yaitu:

a. Seorang da'i harus memperbaiki niat dan motif dalam berdakwah, yakni ikhlas karena mengharap keridhaan Allah Swt.

b. Seorang da'i harus dapat menjadi suri teladan yang baik dalam mengembang dakwah inklusif di tengah masyarakat.

c. Pentingnya da'i dilatih dan di-up grade ilmu pengetahuan dan metodologi dakwah agar lebih efektif dan solutif di tengah masyarakat.

d. Dakwah yang efektif di masyarakat adalah yang menggunakan bahasa yang lugas, mudah diserap, dan dapat dipahami oleh masyarakat (Bugis)

e. Dakwah inklusif disampaikan dengan cara lemah lembut dan hikmah dengan mengedepankan bersifat naratif deskriptif dari pada indoktrinasi

f. Materi dakwah inklusif harus disesuaikan dengan kondisi, kebutuhan,dan dinamika masyarakat kota Parepare

g. Dakwah inklusif yang disampaikan kepada masyarakat kota Parepare harus memiliki sumber hukum yang jelas dan kuat dari Alquran dan Assunnah.

h. Dakwah inklusif menyampaikan dakwah Islamiyah secara menyejukkan, meningkatkan toleransi, membangun persatuan dan kebersamaan.

i. Dakwah inklusif sesuai dengan akselerasi ilmu pengetahuan dan teknologi, sehingga tetap direspon oleh masyarakat kota Parepare.

j. Dakwah inklusif didesain untuk diselaraskan kemampuan nalar dan pengetahuan serta keyakinan keberagamaan masyarakat kota Parepare.

k. Dakwah inklusif diterapkan berdasarkan pemetaan dakwah di masyarakat kota Parepare.

1. Dakwah inklusif relevan pada masyararakat yang heterogen (majemuk) sebagaimana tipologi masyarakat kota Parepare.

m. Dakwah inklusif berimplikasi kepada perubahan sosial keagamaan, yakni mendorong masyarakat melakukan transformasi kehidupan menuju ke arah yang lebih baik. 
n. Materi dakwah inklusif berbasis nilai-nilai kearifan lokal pada masyarakat kota Parepare sepanjang tidak bertentangan dengan ajaran Islam.

o. Dakwah inklusif bersifat terapan dan da'i dapat menjadi model (suri teladan) yang baik dalam mencontohkan aplikasi keagamaan.

p. Dakwah inklusif yang direspon sebagian besar masyarakat adalah bersifat tanya jawab (dialog) masyarakat kota Parepare.

\section{Masalah dan Solusi Pelaksanaan Dakwah yang Berwawasan Inklusif Di Kota Parepare}

\section{Masalah dakwah Inklusif di Kecamatan kota Parepare}

Problem masyarakat kontemporer yang dalam adalah ketersinggungan satu sama lain di tengah kemajemukan. Dakwah Islamiyah seringkali menjadi sebuah masalah di masyrakat majemuk (plural) karena membawa kegaduhan dan kekacauan sosial. Kecenderungan masyarakat lebih memilih internal karena didorong oleh kompetisi dan ingin memenangkan pertarungan. Model dan strategi dakwah yang lebih menekankan pada "indokrtinasi" dapat mencelupkan pelaku agama kedalam sifat eksklusivisme dan pada gilirannya terjebak dalam ruang truth claim. ${ }^{10}$ Islam merupakan agama rahmah dan agama dakwah seringkali menjadi dangkal oleh ketidaktahuan da'i mendakwahkannya yang terjebak ke dalam truth claim.

Pluralism seringkali menjadi sebuah ancaman intoleran di dalam kehidupan bermasyarakat.Waskito Muhammad berpandangan bahwa pluralisme dapat dilihat dari dua sisi yakni tataran praktis dan tataran idiologis.Dalam tataran praktis, pluralisme dapat diterjemahkan sebagai sikap menghargai perbedaan realitas dan saling menghormati antara pihak-pihak yang berbeda, kita sering mendengar istilah toleransi, kalau dalam Islam kita mengenal istilah tasammuh 'alal ikhtilāf (sikap lapang dada dalam perbedaan pendapat). Sementara dalam tataran idiologis pluralisme adalah sebuah gagasan yang berasumsi bahwa semua

\footnotetext{
${ }^{10}$ Muhammad Alifuddin, "Dakwah Inklusif dalam Masyarakat Segregatif di Aoma dan Ambesakoa Sulawesi Tenggara”, Jurnal Dakwah, Vol. XVI, No. 2 Tahun 2015, h. 191.
} 
agama benar dan sama,yang membedakannya hanya pada masalah interpretatif tapi sama dalam subtantif. ${ }^{11}$ Pandangan tersebut menegaskan bahwa dakwah inklusif sepatutnya mengarahkan umat Islam kepada sikap lapang dada terhadap menyikapi perbedaan.

Terkait dengan masalah dakwah inklusif, ada beberapa yang menjadi temuan masyarakat kota Parepare, yaitu sebagai berikut:

1) Kendala dakwah di masyarakat cenderung fanatisme terhadap salah satu madzhab atau organisasi keagamaan tertentu;

2) Dakwah yang tidak mencerahkan dan mencerdaskan serta justru melahirkan kegaduhan dan kontroversi pada masyarakat;

3) Dakwah inklusif yang disampaikan tidak sesuai dengan situasi dan kondisi serta cara berpikir dan penyelesaian masalah pada masyarakat kota Parepare;

4) Dakwah Islamiyah disampaikan kepada masyarakat dengan tanpa mengindahkan penggunaan bahasa lokal (Bugis);

5) Rekatnya masyarakat kota Parepare terhadap budaya lokal (Bugis) yang memungkinkan cenderung eksklusif menerima ide baru dan sensitif terhadap perbedaan pendapat;

6) Terbatasnya pengetahuan dan wawasan masyarakat kota Parepare dalam bidang ilmu sosial keagamaan;

7) Da'i yang belum kompeten, rendahnya integritas kepribadian, dan berkualifikasi keilmuan yang memadai;

8) Kemampuan komunikasi da'i dan penguasaan bahasa Arab dan Indonesia yang dinilai masih rendah;

9) Rendahnya kemampuan da'i bidang teknologi informasi dan komunikasi.

Berbagai permasalahan da'i dalam mengembangkan dakwah Islamiyah dengan pendekatan inklusif. Hal tersebut diperlukan pemerintah hadir dan dimediasi oleh Majelis Ulama Indonesia dalam membedah dan identifikasi

${ }^{11}$ Waskito, Cukup 1 Gusdur Saja; Sebuah Momen Kontroversi Kebodohan Sistemik dan Kerancauan Berfikir Bangsa (Jakarta: Pustaka Al-Kautsar, 2010),h. 113. 
masalah dakwah dan begitu juga mencari solusi-solusinya. Pemerintah (umara'), ulama, dan umat semestinya didorong untuk bersinergi dalam mengidentifikasi masalah dakwah dan sekaligus mengkaji bersama solusi atas permasalahan dakwah inklusif dan umat.

\section{Solusi Dakwah Inklusif di kota Parepare}

Dakwah Islam yang berbentuk inklusif masih mengalam berbagai tantangan dan masalah, baik secara konseptual maupun kontekstual.Dakwah inklusif penting mendapatkan solusi yang tepat dan relevan agar dakwah Islamiyah berjalan dengan efektif dan tercapai tujuannya.Pada prinsipnya, dakwah inklusif dalam Islam merupakan ikhtiar yang selalu digaungkan, dan keberhasilannya merupakan kehendak Allah Swt. Firman Allah Swt., dalam QS. An-Nahl/16: 125 :

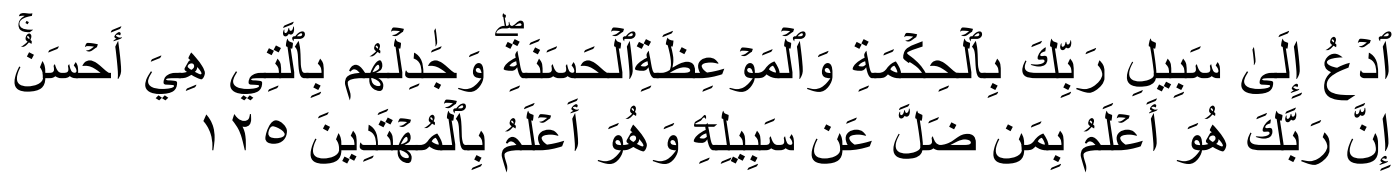

Terjemahnya:

Serulah (manusia) kepada jalan Tuhan-mu dengan hikmah dan pelajaran yang baik dan bantahlah mereka dengan cara yang baik. Sesungguhnya Tuhanmu Dialah yang lebih mengetahui tentang siapa yang tersesat dari jalan-Nya dan Dialah yang lebih mengetahui orang-orang yang mendapat petunjuk. $^{12}$

Strategi dakwah inklusif, sebagaimana ayat di atas, merupakan meotde yang sangat brilian dan dapat digunakan dalam setiap waktu dan tempat. Menyeru dengan cara hikmah yang berbasis ilmu pengetahuan, akhlak, dan ikhsan, merupakan perspektif dakwah yang penting menjadi rujukan oleh setiap da'i. oleh sebab itu, peran da'i sebagai pencipta rasa aman, plus membangunintegrasi sosial dalam masyarakat menjadi semakin urgen ketika da'i tersebut berada dalam bingkai sistim sosial yang tersegregasi. ${ }^{13}$ Dakwah Inklusif memiliki peran strategis

\footnotetext{
${ }^{12}$ Kementerian Agama, Alquran dan Terjemahnya. h.156

${ }^{13}$ Muhammad Alifuddin, "Dakwah Inklusif dalam Masyarakat Segregatif di Aoma dan Ambesakoa Sulawesi Tenggara”, Jurnal Dakwah, Vol. XVI, No. 2 Tahun 2015, h. 184.
} 
jika segmentasi dakwah berada pada wilayah yang sering mengalami korban segregasi, baik secara ideology, politik, maupun secara ekonomi.

Wilayah kota Parepare merupakan masyarakat majemuk (plural) dalam kehidupan sosial keberagamaan.Keberagaman dalam keberagamaan pada masyarakat tampak riskan dan sensitif oleh adanya konflik dan kegaduhan.Upaya dan ikhtiar mengawal masyarakat kota Parepare agar tetap toleran, rukun, dan harmoni menjadi komitmen bagi da'i di seluruh kota Parepare. Oleh sebab itu, konstruksi dakwah yang inklusif, yaitu dakwah yang berpandangan bahwa siapa pun dalam kehidupan ini adalah bagian dari kita. ${ }^{14}$ Pemahaman universal dan pemaknaan yang bijaksana, menjadikan perbedaan sebagai peluang bagi dialektika social menuju sebuah kemajuan dan kejayaan.

Dakwah inklusif sejatinya memberikan edukasi dan motivasi kepada masyarakat melakukan hijrah menuju ke paradigm positif. Islam adalah agama berkemajuan, maka seyogyanya dakwahnya juga mencerminkan dorongan kepada kemajuan.Paradigma dakwah ditekankan pada aspek emansipatoris, transformasi sosial, mengapresiasi humaniora dan pembentukan kesadaran pada objek dakwah (masyarakat mad'u) agartercipta suasana hubungan yang harmonis. ${ }^{15}$ Konteks ini dakwah yang bersifat visioner dan perubahan memang cenderung melahirkan sikap pro-kontra, penolakan, dan perlawanan dari masyarakat. Oleh sebab itu, dakwah inklusif yang dikembangkan di kota Parepare, setidaknya memerhatikan beberapa kondisi berikut:

1) Pentingnya Kementerian Agama dan MUI setempat melakukan pemetaan dakwah inklusif pada masyarakat kota Parepare

2) Pentingnya ada sinergitas antara umara, ulama, dan umat dalam mengembang risalah Islamiyah di tengah masyarakat

${ }^{14}$ Kurniati Syam, "Dakwah dalam Perspektif Modernisme, Antisipasi menuju Postmodernisme," Mediator, vol. 6. No. 1, 2005, h. 4.

${ }^{15}$ La Malik Idris, "Dakwah dalam Masyarakat Plural", Disertasi, Program Pascasarjana UIN Alauddin Makassar, 2009, h. 56. 
3) Pentingnya setiap da'i memahamai dan menguasai bahasa Bugis sebagai bahasa pengantar yang efektif dan efisien dalam berdakwah pada masyarakat kota Parepare

4) Da'i mendapat pendidikan dan pelatihan yang dilakukan oleh Kementerian Agama, agar selalu ter-up date ilmu pengetahuan dan wawasan sosial.

Pada aspek lain, masyarakat kota Parepare sudah mengalami kemajuan dari sisi pendidikan formal, keterbukaan masyarakat terhadap dinamika dari luar, pemanfaatan teknologi informasi cukup tinggi, dan beberapa masyarakat urban menjadi penghuni kota Parepare, hal tersebut menjadi alasan utama dan urgensi dakwah inklusif di masyarakat. Diskursus tersebut, pentingnya dakwah inklusif pada masyarakat kota Parepare, yaitu sebagai berikut:

1) Dakwah inklusif sangat penting untuk merawat dan memperkuat persatuan dan kesatuan dalam bingkai Republik Indonesia;

2) Dakwah inklusif sangat penting melihat masih rendahnya pengetahuan masyarakat terhadap syariat, agama, dan keislamannya;

3) Dakwah inklusif penting untuk memotivasi iman dan pengetahuan yang sinergis dan berkeseimbangan;

4) Dakwah inklusif sangat penting untuk menginterpretasikan Islam secara kaffah dan mengembang misi agama rahmatan lil alamin;

5) Dakwah inklusif sangat penting sebagai representasi dari dakwah Islam secara komprehensif, lintas sektoral dan madzhab, sehingga dapat mempersatukan umat.

6) Dakwah inklusif di kota Parepare senantiasa dibutuhkan karena senantiasa memberikan edukasi positif dalam merawat toleransi dan kerukunan beragama;

7) Dakwah inklusif senantiasa disambut positif oleh masyarakat karena menghargai nilai-nilai kearifan lokal sebagai bagian dari interpretasi Islam yang lebuh membumi di masyarakat; 
8) Dakwah inklusif selalu mendapat tempat di kota Parepare karena memberikan syiar Islam tanpa tiada henti karena mengikuti dinamika perkembangan sosial dan ilmu pengetahuan dan teknologi

Kehadiran strategi dakwah inklusif pada masyarakat kota Parepare telah tampak perubahan signifikan di tengah masyarakat. Masyarakat kota Parepare adalah masyarakat yang dinamis, kompleks, dan selalu membutuhkan pendampingan dakwah inklusif, sehingga konsepsi dakwah inklusif menjadi hal penting dirumuskan. Adapun paradigma dakwah inklusif di kota Parepare, adalah:

1) Paradigma dakwah inklusif ke depan harus bersifat komprehensif, melihat komponen dakwah inklusif sebagai sesuatu yang penting dan saling terkait satu sama lain;

2) Dakwah inklusif harus menjangkau seluruh aspek kehidupan masyarakat, sosialisasi dan mobilisasi dakwah inklusif penting dilakukan agar masyarakat memiliki pemahaman Islam yang berkearifan dan bijaksana;

3) Dakwah inklusif sebaiknya memiliki silabi yang komplit sebagai panduan da'i dalam menyebarkan Islam rahmatan lil alamin;

4) Dakwah inklusif seharusnya yang mencerahkan, menuntun masyarakat bersifat terbuka, menciptakan kehidupan toleran dan rukun, serta mengajak meningkatkan keimanan dan ketakwaan kepada Allah Swt;

5) Dakwah inklusif seharusnya ditopang oleh profil da'i yang kompeten, cinta terhadap dakwah, ikhlas dalam berdakwah, kreatif, komunikatif, netral, dan memotivasi masyarakat menyebarkan Islam dengan penuh kasih sayang.

\section{PENUTUP}

\section{Kesimpulan}

Orientasi materi dakwah yang berwawasan inklusif di kota Parepare meliputi da'i harus ikhlas, da'i menjadi teladan, da'i selalu belajar dan mengupgrade ilmu pengetahuan, dakwah inklusif dengan bahasa local dan cara yang lugas, dakwah yang bersifat naratif-substantif tanpa indoktrinasi, dakwah yang 
sejuk dan bil hikmah, dakwah yang sesuai kebutuhan mad'u, sesuai perkembangan Ipteks, dan tingkat nalar dan pengetahuan mad'u. Dakwah inklusif dilaksanakan berdasarkan peta dakwah, relevan pada masyarakat plural, mendorong transformasi sosial, bersifat terapan, dan dilakukan secara dialogis.

Kendala dakwah berwawasan inklusif diantaranya, dakwah di masyarakat cenderung fanatisme terhadap salah satu madzhab atau organisasi keagamaan tertentu, dakwah yang tidak mencerahkan dan mencerdaskan serta justru melahirkan kegaduhan dan kontroversi pada masyarakat, dakwah inklusif yang disampaikan tidak sesuai dengan situasi dan kondisi serta cara berpikir dan penyelesaian masalah pada masyarakat kota Parepare, dakwah Islamiyah disampaikan kepada masyarakat dengan tanpa mengindahkan penggunaan bahasa lokal (Bugis), rekatnya masyarakat kota Parepare terhadap budaya lokal (Bugis) yang memungkinkan cenderung eksklusif menerima ide baru dan sensitif terhadap perbedaan pendapat dan sebagainya.

Solusi atas kendala dakwah berwawasan inklusif yang ada di masyarakat kota Parepare, seperti kementerian Agama dan MUI setempat melakukan pemetaan dakwah inklusif pada masyarakat kota Parepare, sinergitas antara umara, ulama, dan umat dalam mengembang risalah Islamiyah di tengah masyarakat, setiap da'i memahamai dan menguasai bahasa Bugis sebagai bahasa pengantar yang efektif dan efisien dalam berdakwah pada masyarakat kota Parepare, da'i mendapat pendidikan dan pelatihan yang dilakukan oleh Kementerian Agama, agar selalu ter-up date ilmu pengetahuan dan wawasan sosial, dakwah inklusif bersifat komprehensif, melihat komponen dakwah inklusif sebagai sesuatu yang penting dan saling terkait satu sama lain dan sebagainya.

\section{DAFTAR PUSTAKA}

Alquran al-Karim dan al-Hadits

Abdul Muis, Andi. Komunikasi Islam, Bandung: PT. Remaja Rosdakarya, 2001.

Abdul Baqi, Muh. Fuād. Al-Mu’jam Al-Mufharras lî Alfazh Alquran, Cairo: Dar Al-Kutub Al-`Arabiyyah, t.t. 
Bungin, Burhan. Sosiologi Komunikasi: Teori, Paradigma Dan Diskursus Teknologi Komunikasi Di Masyarakat, Cet. IV; Jakarta: Kencana Prenada Media Group, 2009.

Halim al-Mahmad, Ali Abd.Al-Da'wah al-Islamīyah Da'wah Alamīyah, Kairo: Majlis al-A'la Lì Su'un al-Islamīyah, 1969.

Haramain, M., 2012. Pemikiran dan Gerakan Dakwah Tuan Guru M. Zainuddin Abdul Madjid di Lombok NTB (Doctoral dissertation, Universitas Islam Negeri Alauddin Makassar).

Haramain, M., 2017. DAKWAH DALAM ARUS GLOBALISASI MEDIA: PELUANG DAN TANTANGAN. KOMUNIDA: MEDIA KOMUNIKASI DAN DAKWAH, 7(1), pp.60-73.

Haramain, M. (2016). al-Wasathiyyah wa Atsaruha fi al-da'wah al-Islamiyyah: Dirasah Lugawiyyah Manhajiyyah. Langkawi: Journal of The Association for Arabic and English, 2(1), 83-100.

Maslaw, Abraham. Motivasi dan Keperibadian, Jakarta: Pustaka Binaman Pressindo, 1993.

Madjid, Baihaqi Abd. dan Syaifuddin A. Rasyid, Paradigma Baru Ekonomi Kerakyatan Sistim Syariah: Perjalanan Gagasan dan Gerakan BMT di Indonesia, Jakarta: PINBUK, 2000.

Madjid, Nurcholish. "Cita - Cita Politik Kita", dalam Bosco Carvallo dan Dasrizal, ed., Aspirasi Umat Islam Indonesia. Jakarta: Leppenas, 1983.

Munir, M. et.al.,Metode Dakwah (ed). revisi, Cet. III; Jakarta: Kencana Prenada Media Group, 2009.

Mulkan, Abd. Munir.Ideologi Dakwah: Pemikiran KH. Ahmad Azhar Basyir, Yogyakarta: Pustaka Pelajar, 2000.

Munir Amin, Samsul. Rekonstruksi Pemikiran Dakwah Islam, Jakarta: AMZAH, 2008.

Natsir, Muhammad, Fiqhud Da'wah, Jakarta: Media Dakwah, 2000.

Seha, H. Sampo. Wawasan Alquran Tentang Amar Ma'ruf Nahi Munkar: Aplikasinya Dalam Dakwah (disertasi), Makassar: PPs UIN Alauddin Makassar, 2010.

Shihab, M. Qurais. Wawasan Alquran, Cet. II; Bandung: Mizan, 2007. 